\section{REVISTA}

Actualidades Investigativas en Educación

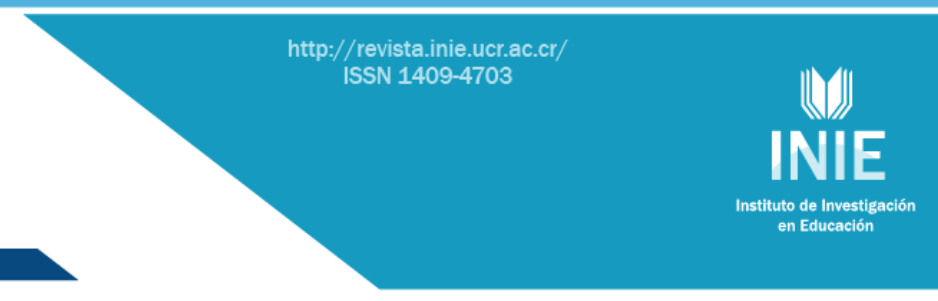

\title{
EDUCAÇÃO TECNOLÓGICA: UMA NOVA PERSPECTIVA PEDAGÓGICA
}

EDUCACIÓN TECNOLÓGICA: UNA NUEVA PERSPECTIVA PEDAGÓGICA TECHNOLOGICAL EDUCATION: A NEW PEDAGOGICAL PERSPECTIVE

\section{Volumen 12, Número 3 \\ Setiembre-Diciembre}

pp. $1-25$

Este número se publicó el 30 de setiembre de 2012

Mariza Rotta

Everton Marcos Batistela

Revista indizada en REDALYC

Revista distribuida en las bases de datos:

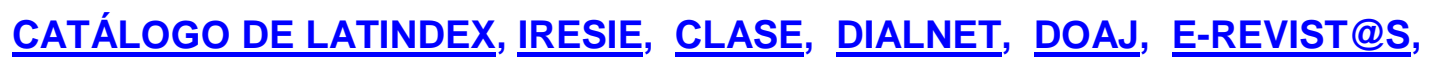

Revista registrada en los directorios:

ULRICH'S, REDIE, RINACE, OEI, MAESTROTECA, PREAL, CLASCO 


\title{
EDUCAÇÃO TECNOLÓGICA: UMA NOVA PERSPECTIVA PEDAGÓGICA EDUCACIÓN TECNOLÓGICA: UNA NUEVA PERSPECTIVA PEDAGÓGICA TECHNOLOGICAL EDUCATION: A NEW PEDAGOGICAL PERSPECTIVE
}

\author{
Mariza Rotta ${ }^{1}$ \\ Everton Marcos Batistela ${ }^{2}$
}

\begin{abstract}
RESUMO: Identificar no contexto escolar a percepção docente de como estão sendo utilizadas às novas tecnologias, discutindo a inclusão da informática na educação, com ênfase aos aspectos de mediação que professores e gestores fazem desses recursos disponíveis, ou seja, de como o conhecimento é tratado em um recurso didático-pedagógico via computador ou outro recurso. Para demonstrar essa relevância os dados levantados por meio da pesquisa aplicada aos professores, gestores e responsáveis da Secretaria Municipal de Educação e Núcleo Regional de Educação, do Município de Dois Vizinhos - Paraná, Brasil, serviu de apoio para a análise e reflexão sobre questões relativas à utilização destes recursos educativos, demonstrado a importância desses no meio educativo e na sociedade a partir de uma nova concepção pedagógica e metodológica, tendo em vista a ampliação desta discussão, nas novas relações de conhecimento, cultura, tecnologia e sociedade, como forma de instrumentalização para inovação na aprendizagem.
\end{abstract}

Palavras Chave: TECNOLOGIAS NA EDUCAÇÃO, INTERAÇÃO SOCIAL, PROCESSO DE ENSINOAPRENDIZAGEM, BRASIL

RESUMEN: Este artículo procura identificar en el contexto escolar la percepción docente sobre cómo están siendo utilizadas las nuevas tecnologías, discutiendo la inclusión de la informática en la educación, con énfasis en los aspectos de mediación que docentes y gestores hacen de estos recursos disponibles, o sea, sobre cómo el conocimiento es tratado en un recurso didáctico-pedagógico vía computadora u otro recurso. Para demostrar esa relevancia, los datos recolectados, por medio de una investigación tipo exploratoria, aplicada a los maestros, gestores y responsables de la Secretaría Municipal de Educación y Núcleo Regional de Educación, del Municipio de Dos Vecinos-Paraná, Brasil, sirvió de apoyo para el análisis y la ponderación sobre cuestiones relativas a la utilización de estos recursos educativos, se demuestra la importancia de estos en el medio educativo y en la sociedad en general, desde una nueva concepción pedagógica y metodológica. Se asume como perspectiva una ampliación de esta discusión, en las nuevas relaciones de conocimiento, cultura, tecnología y sociedad, como forma de instrumentalización para innovación en el aprendizaje.

Palabras clave: TECNOLOGÍAS EN LA EDUCACIÓN, INTERACCIÓN SOCIAL, PROCESO DE ENSEÑANZAAPRENDIZAJE, BRASIL

ABSTRACT: This article search identify in the school context the educational perception as they are being used the new technologies, arguing the computer science inclusion in the education, with emphasis in the aspects of how educational mediation and managers do of these available resources, in other words, like the knowledge is treated in a didactic-pedagogical resource via computer or another resource. To demonstrate this relevance, the compiled data, by means of an exploratory investigation kind, applied to the teachers, managers and responsible for the Education Education and Regional Nucleus Municipal Secretariat, of the Municipal district of Two Neighbors-Paraná, Brazil, serves of support for the analysis and for ponderação about relative matters to the utilization of these educational resources, it demonstrates the importance of these in the middle educational and in the society in general, of a new pedagogical and methodological conception. It takes over as perspective an enlargement of this discussion, in the knowledge new relations, culture, technology and society, like instrumentalização form for innovation in the learning.

Key words: TECHNOLOGIES IN THE EDUCATION, SOCIAL INTERACTION, TEACHING - LEARNING PROCESS, BRAZIL

${ }_{1}$ Professora Assistente da Faculdade Vizinhança Vale do Iguaçu. Doutoranda em Educação pela Universidade Católica de Santa Fé - UCSF, Brasil. Correio eletrônico: mzrotta@yahoo.com.br

${ }^{2}$ Professor Assistente da Faculdade Vizinhança Vale do Iguaçu. Doutor em Sociologia pela Universidade Federal do Paraná, Brasil. Correio eletrônico: e.batistela@hotmail.com

Artículo recibido: 20 de marzo, 2012

Aprobado: 20 de setiembre, 2012 


\section{Introdução}

Analisar a educação tecnológica como um novo diferencial no processo de ensino aprendizagem é uma forma de contribuição para o meio pedagógico. Mesmo que de forma modesta se torna um novo mecanismo capaz de criar uma força sensibilizadora e atrativa para a qualificação dos professores e à utilização das novas tecnologias de informação e comunicação na educação, tornando-se ferramenta que abrange grandes potencialidades.

De modo geral, a polêmica em torno do impacto das novas tecnologias, em particular das que lidam diretamente com a informação e a comunicação sobre o processo educacional, tem sido mal conduzida. A discussão amiúde vem se reduzindo a algumas de suas facetas menores, deixando à margem o que importa ser, de fato, considerado.

O ritmo acelerado das mudanças tecnológicas certamente ocasionou, neste novo século, profundas fissuras tanto no éthos acadêmico quanto na própria ecologia cultural. Uma das conseqüências deste processo nos meios intelectuais tem sido uma profunda revitalização do conceito de realidade virtual, para o âmbito educativo. Tal fenômeno vem ocasionando uma radical transformação no conceito de conhecimento. Onde, a educação, sendo um processo humano e social, acontece pela interação, e a tecnologia, neste caso, é apenas um meio e não um fim. Ou seja, mais do que uma rede de computadores, estamos diante de pessoas se relacionando, se entendendo e aprendendo em rede (Azevedo, apud Maia e Mattar, 2008, p. 18). Que, por sua vez, vem anunciando uma não menos radical reorientação do processo educacional cujas futuros direcionamentos se revelam, simultaneamente, instigantes para o direcionamento do trabalho professor no meio educacional.

Diversos autores têm chamado à atenção para a importância dos recursos oferecidos pelos ambientes digitais para o processo educativo (Moran, 2011; Almeida, 2006; Silva, 2006; Maia, 2008). Não apenas pela possibilidade de buscar informações contidas em bibliotecas, universidades, livrarias, anais de eventos, como também por auxiliar o professor no processo mediativo, utilizando novos métodos de interação com o aluno, como a participação em chats, fóruns, listas de discussões, videoconferências, redes sociais e utilização de softwares educativos.

Esses recursos podem ser trabalhados de várias formas a fim de desenvolver suas potencialidades, explorar conhecimentos, abrir discussões envolvendo os conteúdos vistos 
em aula, discutindo, dialogando com colegas interessados pelo tema, com especialistas da área, atuando sobre objetos de conhecimento e interagindo entre grupos de pessoas.

A interação é o elemento fundamental desse contexto tecnológico educacional que valoriza a aprendizagem. É um termo que remete à idéia de comunidade e de aprendizagem colaborativa. As inúmeras possibilidades de interação com os outros, ou seja, a partilha de opiniões, sugestões, críticas, e visões alternativas podem ser utilizadas na educação em conjunto com materiais didáticos e em diversas atividades pedagógicas, uma vez que o professor estimule no ambiente de ensino a busca pelo conhecimento e desenvolvimento intelectual do estudante.

Essa aprendizagem colaborativa favorecida pelo uso das mídias na educação pode favorecer a oportunidade do aluno em chamar para si a responsabilidade pela própria aprendizagem, de desenvolver o pensamento crítico e criar seu próprio conhecimento.

Contudo, a utilização de recursos de um ambiente digital provoca mudanças nas estruturas educacionais, necessidade de ajustes no processo de formação de professores, sendo necessário repensar o modelo tradicional de construção, avaliação e socialização da produção de conhecimento desenvolvida pelos alunos.

\section{Tecnologias versus contexto educativo}

O decorrer histórico do desenvolvimento tecnológico educacional ganhou maior apoio e rapidez nas suas propostas a partir da segunda metade do século $\mathrm{XX}$, principalmente depois da Segunda Guerra Mundial que acelerou o processo de inovações e expansões tecnológicas.

Percebe-se que a sociedade esta passando por transformações nas formas de se organizar, produzir, comercializar, divertir, de ensinar e também de aprender. Vivencia-se enfim, a era da tecnologia, sem duvida, as tecnologias permitem ampliar o conceito de aula, de espaço e tempo, tornando-a mais atrativa aos alunos, porém, a dificuldade está nas pessoas que precisam manusear essa tecnologia para que as aulas se tornem realmente mais participativas. De acordo com Masetto (2007, p. 152), “(...) uma vez que podemos usálas para dinamizar nossas aulas (...), torna-os mais vivos, interessantes, participantes, e mais vinculados com a nova realidade de estudo, de pesquisa e contato com os conhecimentos produzidos". Portanto, não bastam às tecnologias por si só, é necessário que o professor ao utilizá-las faça de maneira aberta para que haja a participação na criação do conhecimento, 
relacionadas com as novas exigências e que venham de encontro às expectativas dos alunos."

A criação e disseminação de novas tecnologias que interliga computadores de todas as partes do mundo e consequente desenvolvimento de outras formas de transmissão de conteúdos, além dos livros, tem levado a novas experiências e formas de promover a aprendizagem (Azevedo, 2011; Silva, 2006; Maia e Mattar, 2008).

Os atuais softwares educacionais evoluíram muito desde os primeiros tutoriais como ferramentas de aprendizagem. A própria sala de aula tradicional, com encontros presenciais, é transformada e até mesmo substituída. Para se investir em uma formação de qualidade, interagindo com formadores, colegas e com conteúdos das mais diversas áreas de aprendizagem, torna-se necessário aprender a se movimentar, comunicar e interagir nesse outro universo, ou, melhor, em um espaço puramente relacional, cuja realidade material ou localização geográfica não tem a menor importância (Azevedo, 2000).

Perrenoud (2000) relata que as tecnologias aplicadas à educação podem reforçar a contribuição dos trabalhos pedagógicos e didáticos contemporâneos, pois permitem que sejam criadas situações de aprendizagem ricas, complexas e diversificadas.

A internet possibilita acesso gratuito a recursos como sites, serviços de busca de informação como o Google, e correspondência eletrônica ou e-mail, fóruns de discussão (newsgroups), blogs, chats, videoconferências, compartilhamento de documentos como slideshare, vídeos do youtube, redes sociais como o twitter, facebook, Orkut, softwares educativos como jogos e simulações, ferramentas colaborativas como as wikis, além dos próprios ambientes virtuais de educação à distancia como o Moodle e o Amadeus que permitem potencializar atividades de aprendizagem através da Internet em um curso à distância.

Tajra (2001) afirma que a internet traz muitos benefícios para a educação. Com ela é possível facilitar as pesquisas, sejam grupais ou individuais, e o intercâmbio entre os professores e alunos, permitindo a troca de experiência entre eles. Pode-se rapidamente tirar dúvidas, sugerir fontes de pesquisas e a preparação de aulas será mais dinâmica.

É possível, por exemplo, por meio da busca de informações significativas em sites, a compreensão, representação e resolução de situações problema. Portais educacionais estão repletos de recursos e conteúdos disponibilizados de forma gratuita e tem como objetivo servir de auxílio a professores na elaboração e execução de suas aulas, na didática, na 
orientação educacional, em áreas do conhecimento, bibliografias, resenhas e artigos temáticos. O próprio governo brasileiro possui vários portais que visam estimular o uso e aprendizagem de novas tecnologias na busca de melhor utilização no processo de ensino e aprendizagem.

Outro exemplo é a utilização do GoogleDocs, gratuito, online e permite a colaboração na edição dos documentos como a produção de textos colaborativos, criação de glossários dinâmicos, uso de planilhas eletrônicas para a criação de gráficos muito utilizados na disciplina de matemática, uso de apresentação de slides para seminários, de formulários online para a criação de questionários, pesquisas, testes ou provas e a disponibilização de qualquer um desses docs na internet e sua incorporação em um blog, por exemplo.

Uma apresentação de slides que sem a internet seria restrita à sala de aula, pode ser convertida em vídeo com o auxilio de software específico de conversão e disponibilizada no youtube ou numa rede social como o Twitter. O uso de jogos e simulações como os objetos de aprendizagem disponíveis online estimulam o desenvolvimento de várias habilidades e muitos conhecimentos são construídos de forma lúdica, interativa e estimulante.

Recursos como o correio eletrônico (e-mail), por exemplo, que além de permitir a troca de mensagens acelerada, permite, principalmente, que uma mesma mensagem seja disseminada rapidamente para várias pessoas, favorecendo, por exemplo, a formação de um espaço coletivo de aprendizagem, e que pode durar vários dias, como também acontece em fóruns temáticos.

Ocorre, então, um diálogo de mensagens que antes, só seria possível se os envolvidos estivessem em um mesmo espaço físico, ou em um mesmo horário, falando ao telefone, por exemplo.

É possível dar início a uma conversa através da troca de mensagens via e-mail e continuá-la num encontro virtual "em tempo real" numa sala de chat, para, em seguida, concluí-la novamente através do e-mail. A temporalidade que é experimentada em tais ambientes é de natureza diversa daquela introduzida pela escrita e que permitiu que nossas sociedades se sentissem participantes de uma única História. Uma nova temporalidade que se precisa aprender a administrar e a agendar (Azevedo, 2011).

Maia e Mattar (2008) destacam que o movimento construtivista é combinante com a filosofia da educação online, já que concebe o conhecimento como processo contínuo de construção, criação, descoberta e ressalta a importância da interação do sujeito com o 
ambiente, os objetos culturais e os outros seres humanos. Trata-se de uma concepção (ou modelo) educacional que privilegia a problematização, a autoria, a reflexão e o diálogo, incentivando o espírito colaborativo, a constituição de comunidades e/ou redes de conhecimento, o trabalho em conjunto a partir de modelos menos estruturados e hierarquizados de desenvolvimento.

Azevedo (2011) faz uma analogia ao passado escolar, lembrando que os professores foram preparados para o ambiente educacional presencial - sala de aula, lousa, giz -, de modo que se aprendeu como se comportar e agir nesse ambiente. O autor coloca que é preciso uma espécie de pré-escola virtual.

Com as milhares de informações que estão ao alcance de todos, o trabalho isolado do professor já não satisfaz mais. As mudanças de postura, a quebra de paradigmas, o trabalho em conjunto, cooperativo vem de encontro com as necessidades dos alunos na busca da construção do conhecimento e o professor entra como mediador, orientador deste conhecimento, aquele que mostra os caminhos para seus alunos em conjunto para buscarem de forma interativa o saber e a construção de novos saberes.

Almeida (2006) destaca que na educação com suporte em ambientes virtuais, o papel do professor é o de gerir as situações facilitadoras da aprendizagem, articular diferentes pontos-de-vista, instigar o diálogo entre alunos e a produção conjunta, a busca de informações e a expressão do pensamento do aluno, orientando-o em suas produções, na recuperação, análise dos registros e suas respectivas reformulações.

Neste ambiente o professor continuará sendo professor, mas um professor mediador e orientador e não mais o detentor do conhecimento. No momento em que se está participando ativamente com o meio, aprende-se e transmite-se conhecimentos. E para se obter resultados positivos, o trabalho deve ser cooperativo, colaborativo e interativo.

Cooperativo no sentido dos trabalhos em grupos, onde todos participam, contribuírem de forma conjunta para atingir os objetivos comuns do grupo. Esse trabalho pode ser feito através do chat, MSN, com o compartilhamento de arquivos on-line, entre outros. Colaborativa através da troca de materiais encontrados, onde individualmente, cada integrante do grupo dá sua contribuição, podendo ser através de uma lista de discussão, email, etc. E Interativa no sentido de tornar o trabalho integrado, onde todos possam interagir para que o trabalho em grupo se torne significativo para os participantes. 
Chaui afirma (1997) em sentido antropológico, não falamos em cultura, mas em culturas, no plural, pois a lei, os valores, as crenças, as práticas e instituições variam de formação social para formação social. Isso impele a aprofundar estudos sobre o conceito "cultura", ampliando o campo de visão a respeito da abrangência de seu real significado.

Deve-se analisar a cultura como uma grande influência na questão da tecnologia, ambas estão influenciadas pelo processo de aperfeiçoamento e mudança que estão ocorrendo na sociedade, isso é de grande relevância para a educação e torna o cotidiano mais acelerado, onde as pessoas precisam acompanhar o processo e adentrarem-se as novas visões que a sociedade revela. O domínio da nova ferramenta tecnológica tem a ver também com as transformações culturais que a sociedade vive e faz com que as pessoas mudem muitas vezes a forma de pensar e agir sobre as novidades das novas atualizações.

Como a sociedade a educação também precisa acompanhar esses processos e trabalhar com os alunos a forma correta de se utilizar a ferramenta tecnológica para que futuramente esta não se torne uma arma contra eles mesmo, no entanto, que ela torne-se um auxiliar no andamento do ensino e acompanhamento dos conteúdos trabalhados pelo professor.

Discutindo aspectos associados ao ambiente cultural nas sociedades informatizadas, Pierre Lévy (1993), mostra que a interatividade de faixas textuais, de agentes operadores e criadores sempre múltiplos e plurais (coletivos abertos) é um traço característico dos modos de cognição e de produção do conhecimento na época em que vivemos. O autor se refere à escrita hipertextual e multimídia da atualidade por meio de uma comparação com a prática da montagem de espetáculos, pratica em que muitos quase que necessariamente interferem para a consecução do resultado.

As grandes transformações ocorridas no cotidiano educacional e social ocorrem pela rápida evolução na vida das pessoas que se em maior parte pelos avanços tecnológicos e das mídias que influenciam a cabeça das pessoas e as transformam em robôs da evolução da sociedade. Sabendo desse avanço sabemos que deve-se trazer a cultura mais junto dos alunos e trabalhar o que a tecnologia e as mídias tem de aproveitável e de prejudicial a todos para que os estudantes saibam com o que estão lidando e possam utilizar de maneira auxiliar para seu conhecimento, que essas evoluções podem ajudar no aprendizado, mas sabendo como manipulá-los para não serem manipulados eles pelas ferramentas 
tecnológicas que estão cada vez mais dentro das casas da sociedade moderna que estamos vivendo.

\section{Metodologia}

Nessa perspectiva, a temática escolhida para a elaboração do presente trabalho, tem como principal objetivo a percepção dos docentes para a utilização das novas tecnologias da informação e da comunicação, em contextos educativos, verificando como são utilizadas as linguagens da comunicação e os recursos das novas tecnologias que envolve o processo de ensino aprendizagem.

Neste limiar recorrere-se à abordagem qualitativa de natureza interpretativa por possibilitar a investigação de forma abrangente da prática pedagógica dos professores sendo, portanto, particularmente útil para a investigação de questões ligadas à vida das pessoas e aos significados que atribuem à compreensão do seu desenvolvimento profissional.

A pesquisa foi aplicada de forma exploratória, buscando dados para confirmar as conclusões apresentadas. Tal pesquisa tem sua validade e necessidade, como observa-se que para:

[...] obter descrições tanto quantitativas como qualitativas do objeto de estudo, 0 investigador deve conceituar as inter-relações entre as propriedades do fenômeno, fato ou ambiente observado. Uma variedade de procedimentos de coleta de dados pode ser utilizada, como entrevista, observação participante, análise do conteúdo etc., para estudo relativamente intensivo de um pequeno número de unidades [...] (MARCONI E LAKATOS, 2007, p.85)

A análise é exploratória pelo fato que busca dados do ambiente onde a pesquisa acontece, oportunizando-nos conhecer o local, analisar as hipóteses levantadas, familiarizando-se com o contexto, que no momento da pesquisa nos possibilitou identificar precisamente os desafios propostos.

Além de exploratória a pesquisa também foi realizada de forma descritiva. Onde as hipóteses apresentadas encontraram elementos claros para solidificar-se. 
A pesquisa descritiva observa, registra, analisa e correlaciona fatos ou fenômenos (variáveis) sem manipulá-los. Procura descobrir, com a precisão possível, a frequência com que um fenômeno ocorre, sua relação e conexão com outros, sua natureza e características. Busca conhecer as diversas situações e relações que ocorrem na vida social, política, econômica e demais aspectos do comportamento humano, tanto do indivíduo tomado isoladamente como de grupos e comunidades mais complexas (CERVO E BERVIAN, 1996, p.49).

Tal pesquisa descritiva nos auxiliou para a observação, análise e interpretação dos acontecimentos, através da qual obtemos novas percepções e descobrimos novas idéias. A pesquisa bibliográfica, oportunizou o contato com dados já estudados para dar clareza a investigação. Tal pesquisa possui valor para a validação das hipóteses.

[...] a pesquisa bibliográfica procura explicar um problema a partir de referências teóricas publicadas em documentos. Pode ser realizada independentemente ou como parte da pesquisa descritiva ou experimental. Em ambos os casos, busca conhecer e analisar as contribuições culturais ou científicas do passado existentes sobre um determinado assunto, tema ou problema. (CERVO E BERVIAN, 1996, p.48).

Serviu como base no levantamento de hipóteses que contribuíram, por meio de acontecimentos do passado, no entendimento do objeto estudado, fazendo a relação do ontem com o hoje, analisando suas mudanças durante esse intervalo de tempo.

A pesquisa de campo, para esta seara torna-se necessária para apresentar elementos para a análise. Trazendo fundamento para compreender as informações referentes ao problema bem como suas novas relações com os diversos aspectos dos locais pesquisados. (Marconi e Lakatos, 2009, p.188)

A pesquisa procurar compreender como as concepções são articuladas na prática docente, a partir de dados coletados com a equipe escolar composta por: diretores eleitos pela comunidade escolar; professores que fazem parte da equipe escolar de um Colégio Estadual e uma Escola Municipal, representante da Secretaria da Educação Municipal e do Núcleo de Educação Estadual (CRTE) que acompanha e assessora as atividades técnicoadministrativas e pedagógicas, do Município de Dois Vizinhos - Pr. Considerando que são responsáveis pela implementação das políticas de tecnologias aplicadas à educação em 
espaços educativos que possuem limitados recursos tecnológicos. Como apenas um laboratório por escola com quarenta equipamentos para atender a todas as demandas oriundas do trabalhos docente e discente, nas salas de aula da rede estadual possuem um aparelho televisor com acesso a pendrive, já na rede municipal há uma sala com televisor que atender a toda clientela. Sendo esses os recursos que esses espaços educativos possuem para implementar o rol de determinações legais que chegam diariamente as escolas por meio de políticas que afirmam a necessidade de um trabalho diferenciado na formação do aluno diante da invasão mundial das novas tecnologias.

Para o levantamento das informações optou-se pela utilização de questionário, como instrumento de coleta de dados, onde foram incluídas questões de cunho objetivo e subjetivo, possibilitando aos pesquisados discorrer de forma espontânea sobre alguns questionamentos.

Os dados obtidos com a investigação foram analisados separadamente buscando generalização quando possível, a fim de perceber como está a percepção dos envolvidos na investigação sobre as TICs. Para tanto a análise dos dados é feita a fim de encontrar pontos convergentes, buscando uma explicação às respostas, de modo a fazer ligação com o conhecimento cientifico, para que se gere conhecimento real do problema estudado.

\section{Análise e discussão de resultados}

O diálogo com a realidade educacional foi oportunizado pela pesquisa de campo, de forma que os dados coletados permitem desvelar os problemas detectados sobre a prática docente e gestora na área pedagógica referente à percepção que possuem sobre utilização de tecnologias da informação e da comunicação no meio educativo. Permitindo um olhar reflexivo sobre as dificuldades e aspirações dos docentes e gestores educacionais dessa realidade. Vislumbrando que um novo horizonte está a se delinear para a ação pedagógica e que se encontra permeado de propostas metodológicas que contam com a TICs, para desencadear a revolução do ensino

Portanto, faz-se necessário que o professor crie um perfil muito diferente daquele que predominou até agora. Frente a isto, alguns assumem os desafios que os novos tempos trazem. Outros ficam parados no tempo e na carreira. O papel do professor tornou-se muito mais relevante a partir das novas exigências sociais e tecnológicas que demandam do aluno uma formação plena e abrangente. A ciência milenar deixou de ser obra terminada e 
dogmática para se abrir ao dinamismo de novos conhecimentos. São tantas as responsabilidades do professor do novo século que é necessário que ele esteja em sintonia com o mundo de informações cada vez mais veloz.

\section{1 Tecnologias desafio à ação docente}

Os sistemas de comunicação e de troca de informações passam por mudanças freqüentes e as inovações tecnológicas acabam agregando-se inevitavelmente à cultura da humanidade. Isso nos dá evidências claras de que novas maneiras de pensar, de conviver estão sendo constantemente elaboradas em nossa sociedade, modificando as relações existentes entre os homens, alterando o processo de produção de conhecimento que influencias na produção de bens materiais, reorganizando o trabalho e nossos processos cognitivos Pierre Lévy (1993). E, concomitantemente a nossa forma de ver e entender o mundo ao nosso redor.

\section{Figura 1}

As tecnologias disponíveis nas Instituições de ensino desafiam os docentes a planejar de modo eficaz sua atividade em sala de aula e desenvolver novos procedimentos?

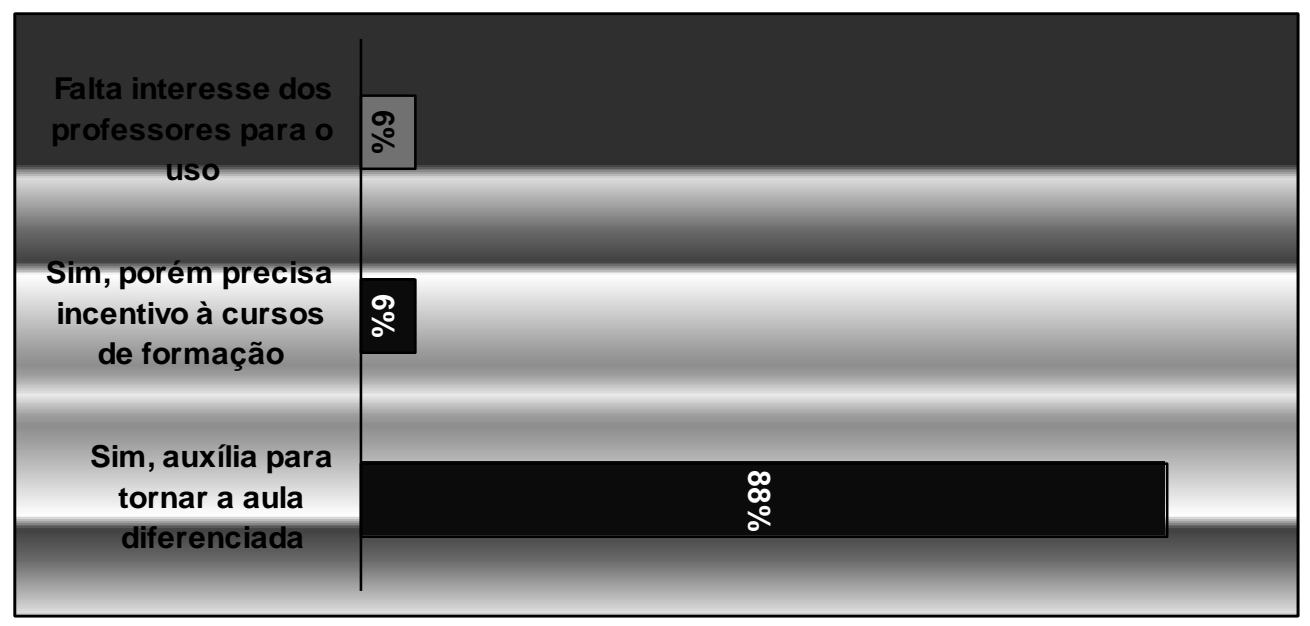

Observa-se que $88 \%$ dos entrevistados consideram que as TICs auxiliam para tornar a aula diferenciada e atrativa para os alunos, pois com o uso das tecnologias durante as aulas, fará com que desperte interesse por parte do aluno, motivando-o a ir à busca de conhecimento alem da sala de aula, bem como contribuindo para que os alunos tenham um breve conhecimento sobre como manusear e utilizar tal tecnologia. 
Percebe-se, porém que alguns profissionais ainda não vêem necessidade ou benefícios do uso de tais tecnologias, e outros não se sentem instigados a capacitação visto que por muito tempo, e até mesmo nos dias de hoje, não se valorizou adequadamente o uso das tecnologias na educação, visando tornar o processo de ensino aprendizagem mais eficiente e eficaz, este fato se dá, pois muitos entendem por educação a transmissão de conhecimentos de forma organizada e sistematizada, exigindo dos educandos a memorização das informações que lhes são passadas e sua reprodução nas provas e avaliações.

A sociedade atual passa por profundas mudanças caracterizadas por uma profunda valorização da informação. Na a chamada sociedade da informação, processos de aquisição do conhecimento assumem um papel de destaque e passa a exigir um profissional critico, criativo, com capacidade de pensar, de aprender a aprender, de trabalhar em grupo e de se conhecer como individuo. Cabe a educação formar esse profissional e para isso, esta não se sustenta apenas na instrução que o professor passa ao aluno e no desenvolvimento de novas competências como: capacidade de inovar, criar o novo a partir do conhecido, adaptabilidade ao novo, criatividade, autonomia, comunicação. É função da escola, hoje preparar os alunos para pensar, resolver problemas e responder rapidamente as mudanças contínuas. (MEC, 2002, p. 12 e 13).

Nos próprios cursos de educação superior, o uso das tecnologias para o processo de aprendizagem e a variação para motivar os alunos não é tão comum, o que faz com que esses novos profissionais ministrem suas aulas, praticamente copiando o modo de fazê-lo e o próprio comportamento de alguns professores de suas graduações, dando aulas expositivas e às vezes sugerindo trabalhos em grupo com pouca ou nenhuma orientação.

Sem dúvida toda essa tecnologia provoca um debate sobre o bom uso dela e de sua mediação por parte dos professores, muitos profissionais saem dos cursos de graduação sem o devido preparo, visto que há poucas décadas foi havendo esta abertura no ensino superior para a formação de competências pedagógicas.

Além destas situações, a desvalorização do uso das tecnologias tem a ver com experiências vividas nas décadas de 1950 e 1960 quando se procurou impor o uso das técnicas nas escolares, esse tipo de ensino era voltado basicamente para formar gente apta 
para o trabalho, o que provocou inúmeras críticas dos educadores da época e uma atitude geral de rejeição ao uso de tecnologias na educação.

\subsection{Aprendizagem mediada pela tecnologia, novos tempos, outros rumos}

A expressão Tecnologia na Educação abrange a Informática na Educação, mas não se restringe a ela. Inclui, também, o uso da televisão, do vídeo, do rádio, do retroprojetor, do DVD, e outros na promoção da educação. O que fascina nas novas tecnologias à nossa disposição, em especial é a Internet, e dentro da Internet a Web, permite criar ambientes ricos em possibilidades de aprendizagem.

Pelas suas características específicas, a realidade virtual encerra em si imensas potencialidades que, nas áreas da educação e da investigação, podem transformar num poderoso instrumento a serviço de todos aqueles que procuram à mudança e a evolução nestes setores.

\section{Figura 2}

Os espaços educativos que trabalha dispõem de ambientes adequados e recursos tecnológicos para uso dos docentes?

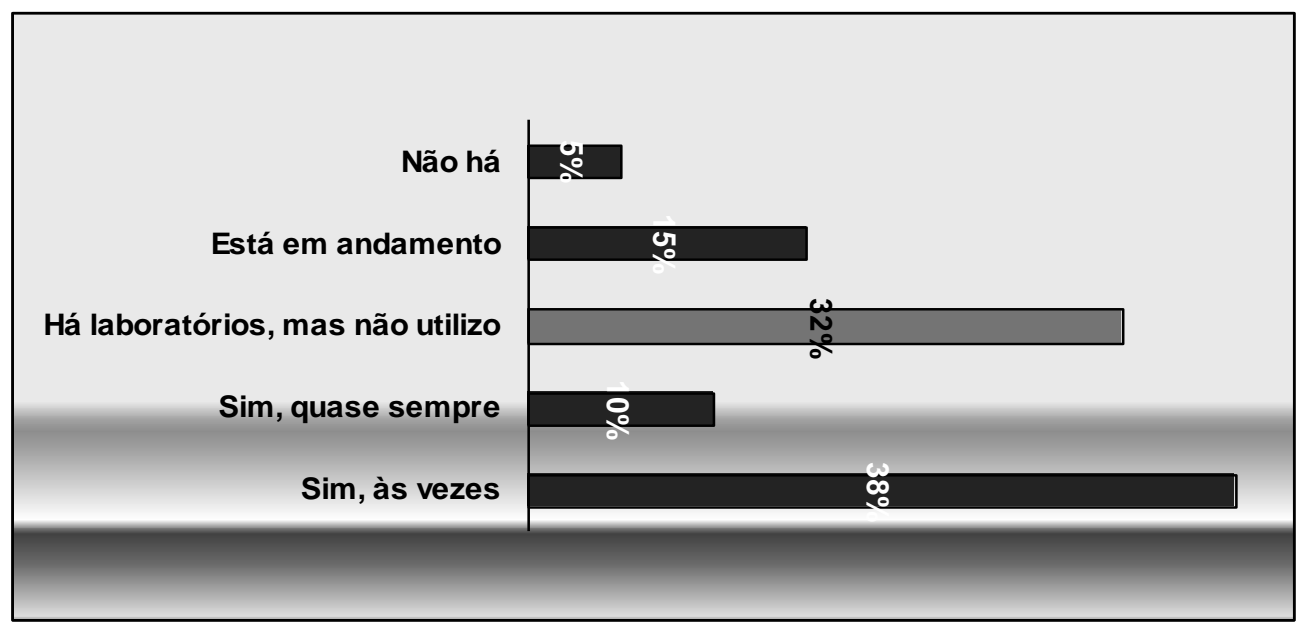

Percebe-se que as escolas estão equipadas com laboratórios e recursos humanos (laboratoristas), ou que estes já estão sendo encaminhados, os quais são utilizados com uma notória freqüência servindo de apoio as práticas docentes. Levando a percepção que evoluí-se tecnologicamente nos últimos anos, sem aprender e explorar todas as possibilidades de cada meio. Atualmente o professor tem um leque grande de tecnologias, que pode estar inserindo e auxiliando-o em sua aula, é importante que o professor faça o 
uso destes meios, identificando qual o auxilia mais, para que use com objetivo de tornar suas aulas atrativas.

Nas escolas se percebe a implantação de laboratórios de informática, como importante recurso para que o educador leve seus alunos para realizarem suas pesquisas, todavia é importante ficar atento, pois há muita facilidade de dispersão, os alunos se perdem no emaranhado de possibilidades de navegação, não procuram o que foi combinado deixandose arrastar para as áreas de interesse pessoal. Ficando evidente a impaciência de alunos por mudar de uma página para outra, assim, essa impaciência faz com que o aluno aprofunde-se pouco nas possibilidades de informações que aquele site ou software oferece.

Os professores estavam acostumados com o aluno padrão ou ideal como se todos fossem homogêneos, e tivessem o mesmo ritmo de aprendizagem, e não com o aluno real, que chega à escola cheio de informação e com muitas perspectivas de uma educação diferenciada, não procuram mais conteúdos prontos e acabados, mas sim relacionados à sua vida concomitante à realidade histórico - social.

Figura 3

Como é a concepção dos docentes com relação à importância do uso das tecnologias na educação?

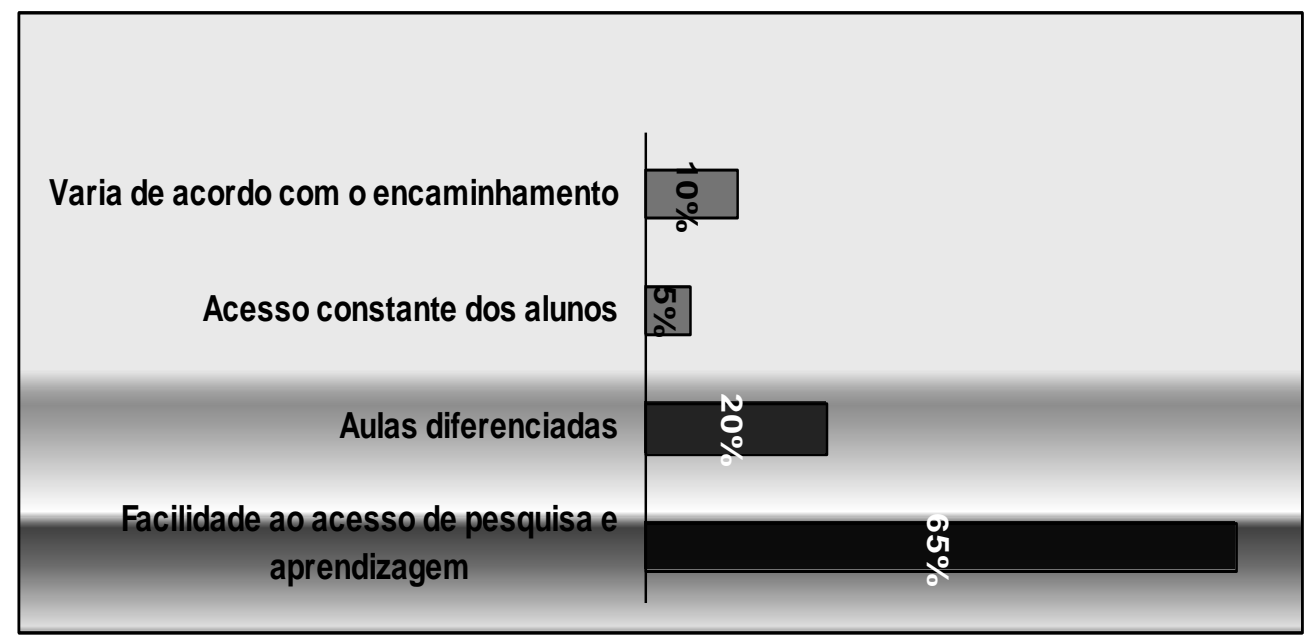

O que justifica a utilização das tecnologias pela maioria dos entrevistados é a facilidade ao acesso de pesquisa, que contribui para a efetivação da aprendizagem multidisciplinar, traduz uma experiência enriquecedora, avoluma conhecimentos, cria ambiente pluridisciplinares, permite um ensino e aprendizagem mais vastos, profundos e integrados, responde a diferentes motivações e objetivos; em seguida verificou-se a viabilidade das 
aulas diferenciadas sendo que o computador deve ser utilizado, não como uma máquina de ensinar, mas como uma ferramenta para aprender, isto é, como uma tecnologia que pode facilitar o desenvolvimento das competências e habilidades necessárias para que aprendam a aprender, pois as tecnologias diminuem distâncias agilizando o aprendizado das pessoas. Movimentando-se no espaço virtual, o participante adquire uma experiência em primeira mão, a informação não Ihe é transmitida por outrem, de modo teórico e essencialmente verbal, sem grandes possibilidades de experimentação, mas é por ele recolhida, de forma direta e pessoal 
Tabela 1

A visão da Secretaria Municipal de Educação e do Núcleo Regional de Educação sobre importância das TICs

\section{Secretaria Municipal de Educação}

As tecnologias são instrumentos fundamentais no contexto escolar, pois os computadores, a internet e demais tecnologias educacionais são subsídios ao professor para o enriquecimento das aulas, tornando-as mais atrativas e de qualidade

\section{Núcleo Regional de Educação}

As tecnologias educacionais auxiliam o trabalho docente, pois possibilitam um envolvimento maior dos alunos com recursos que proporcionam mais interesse na aprendizagem. São essenciais, não só porque permitem dinamizar o ensino, mas também porque por meio delas acontece o aprendizado. Possibilita a inclusão social daqueles que não dominam as tecnologias. Não só torna a aula mais dinâmica, como também é uma ferramenta pedagógica importante para a construção qualitativa do conhecimento.

As políticas públicas de educação têm dado ênfase, ao longo dos últimos anos, à necessidade de informatizar as escolas e modificar práticas de ensino em função da sociedade da informação, visto que além da contribuição para o processo de ensinoaprendizagem, prepara o aluno para a inclusão social emergente nesta era, que perante um novo paradigma educativo, que entende a educação como um processo dinâmico e criativo, que coloca o aluno no centro dos processos de ensino e de aprendizagem, valorizando-o como ser autônomo e completo, capaz de construir o seu próprio saber.

Figura 04

$\mathrm{Na}$ condição de professor tens acesso a oferta de cursos para formação continuada por meio dos TICs?

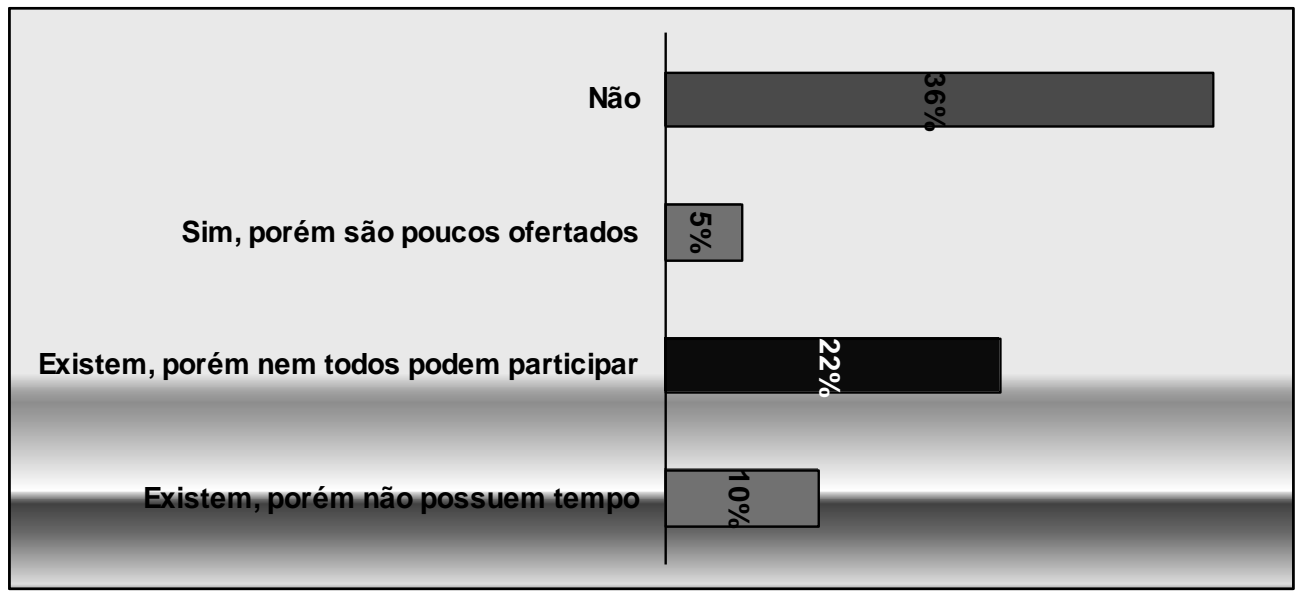


A maioria dos professores, responderam não haver oferta de cursos, e quando existem, estes são de participação restrita, aos membros das equipes gestoras. O que leva a um denominador que tais colocações devem ser analisadas antes de se iniciar 0 planejamento de um projeto, a fim de evitar problemas e resultados desagradáveis, como por exemplo, problemas financeiros para implementação de projetos que necessitam de equipamentos dispendiosos, bem como capacitação a nível de orientação de como trabalhar e usufruir desses recursos que vêem para contribuir na formação continuada dos professores.

Sobre esse novo modelo de formação continuada confrontam-se as respostas dos representantes do Núcleo Regional de Educação e Secretaria Municipal de Educação, com as respostas dos professores conforme dados expostos na Tabela 2.

\section{Tabela 2}

$\mathrm{Na}$ condição de responsáveis pela rede de ensino municipal e estadual deste município, analisa que a formação continuada por meio dos TICs está acontecendo?

\section{Secretaria Municipal de Educação}

No município de Dois Vizinhos ainda não existe o projeto em andamento, mas esta sendo elaborado um projeto em parceria com uma instituição de ensino superior desse município (Faculdade Vizinhança Vale do Iguaçu).

\section{Núcleo Regional de Educação}

(...) tanto o governo federal como estadual desenvolvem projetos de capacitação para os professores, são eles: capacitação dos professores no laboratório do Paraná Digital, o curso do PROINFO em convênio com o MEC e formação de Tutores pelo PDE/SEED".

Diante da transformação que a sociedade vem passando, é importante a preocupação com a Formação Continuada dos professores, pois a cada momento surgem novas tecnologias e o educador deve receber auxilio ou formação continuada para fazer o uso dessas tecnologias. É necessário pensar em uma escola que forme cidadãos capazes de lidar com o avanço tecnológico, participando dele e de suas conseqüências (Sampaio e Leite, 1999, p. 15). É preciso preparar o professor para utilizar pedagogicamente as tecnologias de forma que venha contribuir para o mundo atual e futuro. No entanto, ainda é possível encontrar resistências por parte dos professores com relação à aceitação de 
propostas de formação continuada que agrega discussões de cunho epistemológico e metodológico que contribua de forma qualitativa na formação dos docentes de nossas redes de ensino.

\subsection{Professor ' $x$ ' tecnologia ou professor ' + ' tecnologia}

Do livro, ao quadro de giz, ao retroprojetor, da TV e vídeo, ao laboratório de informática as instituições de ensino vem tentando dar saltos qualitativos, sofrendo transformações que levam junto um corpo de professores, mais ou menos perplexo, que se sente muitas vezes despreparado e inseguro frente ao enorme desafio que representa a incorporação das tecnologias ao cotidiano da sala de aula.

Figura 5

Como analisa o grau de dificuldades ou necessidade com relação ao uso do computador.

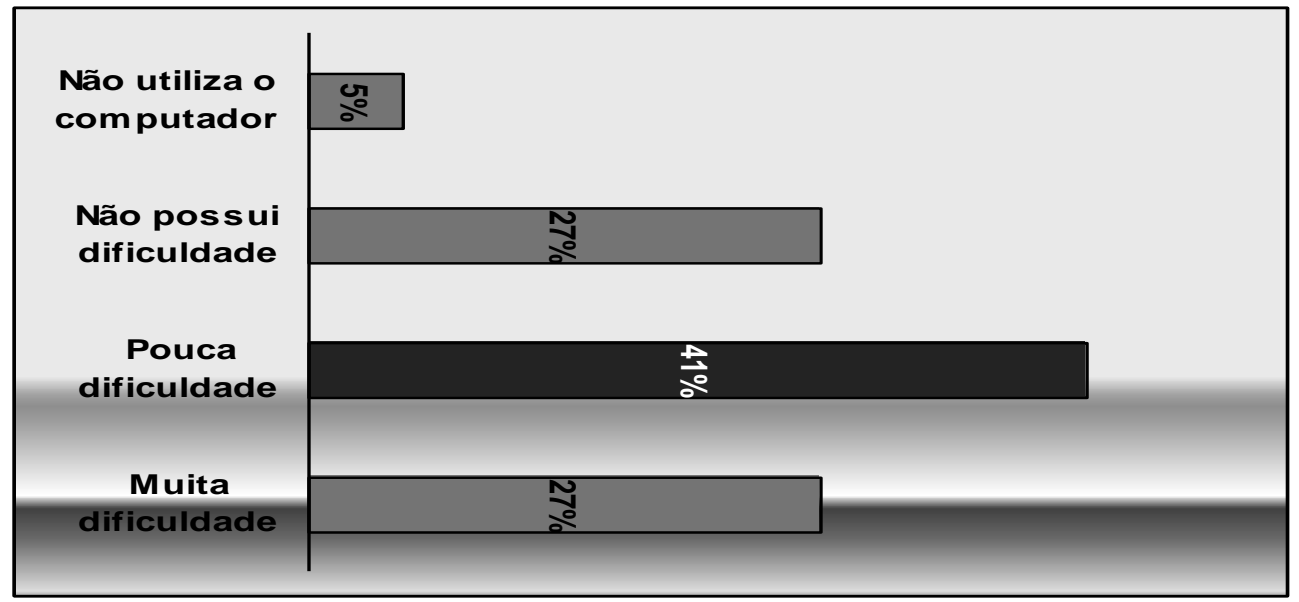

A tecnologia apresenta-se como meio, como instrumento para colaborar no desenvolvimento do processo de aprendizagem, todavia, o computador, ao ser introduzido na escola, funciona como agente perturbador da ordem estabelecida e permite que os que dela discordem se valham dessa oportunidade para questioná-la. O computador provoca essa discussão porque os alunos, em geral, têm muito mais facilidade para lidar com ele do que os professores, e, portanto, se torna um agente subversivo da ordem estabelecida na escola. 
Alguns professores utilizam a tecnologia de forma criteriosa e criativa, muitos a usam de forma estreita e sem imaginação instrumental. Os meios digitais têm enorme potencial para o ensino, mas não é fácil realizar esse potencial se eles são considerados apenas tecnologias e não formas de cultura e comunicação (MEC, 2006, p.9).

Cabe aos professores desenvolver nas crianças uma capacidade crítica que as permita compreender como a informação é produzida, disseminada, utilizada e como ela adquire significado, assim como a alfabetização refere-se à leitura e a escrita, a alfabetização digital também deve envolver leitura critica e produção criativa.

Tabela 3

As escolas da rede municipal e estadual deste município encontram-se equipadas para atender a demanda que requer a utilização das TICs para o desenvolvimento educativo.

\section{Núcleo Regional de Educação}

Todas as escolas do Ensino do Estado receberam um laboratório de informática, acesso a internet, TV multimídia em cada sala de aula, com entrada USB e cartão de memória; TV Paulo Freire; cada professor recebeu um pen drive e orientações para usá-lo; escolas do Ensino Médiorecebera kits com DVD educativos, há ainda o Portal Dia a Dia do Paraná com materiais disponível, alem do portal do MEC. Em convênio com o MEC quatro escolas receberam laboratórios do Proinfo.".

Todavia faz-se necessário ressaltar que é importante que as técnicas sejam escolhidas de acordo com o que se pretende desenvolver com os alunos por meio de tecnologias variadas e adequadas aos mais diversos objetivos. $\mathrm{Na}$ educação, os instrumentos tecnológicos se tornaram grandes aliados, no auxílio pedagógico ao educador. Daí, a necessidade de se repensar o seu papel social. Analisando as modernas tecnologias utilizadas na educação, vê-se que os computadores não fariam mais do que um retroprojetor ou uma fita de vídeo. A grande diferença apresentada pela informática, e também um dos motivos do seu sucesso junto aos alunos, é a desverticalização do ensino. Com a informática, torna-se possível a construção do conhecimento os alunos deixam de ser elementos passivos que apenas recebem informações e passam a ser elementos ativos, sob orientação do professor, construindo e absorvendo conhecimentos. Quando bem aplicada, há uma maior integração entre as partes, ao mesmo tempo em que os alunos se sentem mais livres para questionar as aulas, os professores se tornam mais acessíveis à discussão com os alunos. Isto porque o professor deixa de ser a única fonte de informação. 


\section{Figura 7}

Dos recursos disponíveis nos espaços educativos, qual complementa sua ação pedagógica diária?

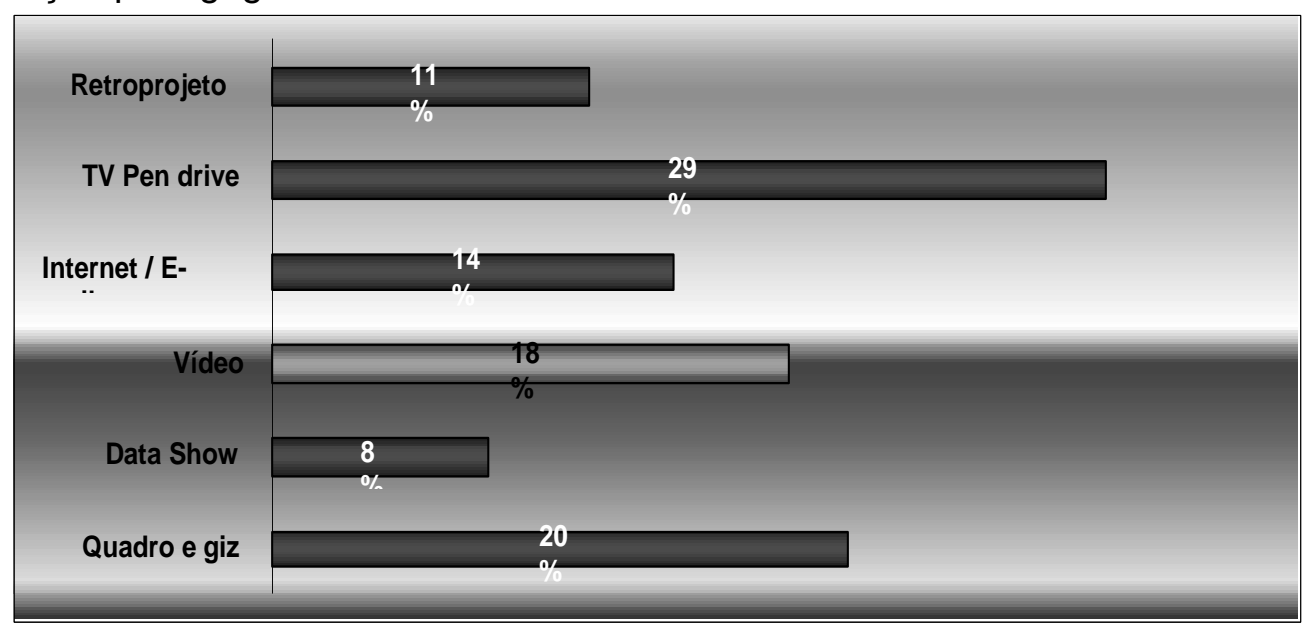

Qualquer projeto de implantação de sistemas de informática dentro das escolas, depende diretamente do professor, isto porque, é sobre ele que recai toda a responsabilidade do sucesso do projeto após a sua implantação. Deve o professor estar preparado para tais mudanças, adquirir o máximo de conhecimento possível para atender aos alunos que já têm a cultura da informática naturalmente, em seu dia-a-dia. As informações surgirão em quantidade e rapidez tamanha, vindas dos softwares instalados nos computadores, dos sites na Internet, dos próprios alunos que já experimentaram e descobriram novidades em sua própria casa, enfim, as fontes de informação irão multiplicarse. Neste novo contexto, o professor passará à função de orientador, direcionando as pesquisas e auxiliando os alunos nas dúvidas existentes na administração todas as novas informações recebidas por meio dos diferentes instrumentos virtuais. 


\section{Tabela 4}

Como analisa as políticas públicas do Estado do Paraná, que oferecem aos professores incentivos acerca das tecnologias educacionais, tanto em nível de investimento didático como de capacitação profissional?

\section{Secretaria Municipal de Educação}

A proposta é maravilhosa, são investimentos que servem para a melhoria da qualidade de ensino e representa o progresso e a evolução da educação.

\section{Núcleo Regional de Educação}

No contexto Federal o Paraná é um estado de destaque acerca das tecnologias educacionais e em investimentos na capacitação e nos recursos tecnológicos. Em cada um dos 32 núcleos de educação há equipes para acessória técnica e pedagógica, além de proporcionar acesso à internet, recursos didáticos produzidos por e para professores (projetos Folhas e OAC, TV Paulo Freire), entre outros. Essas práticas são positivas, pois possibilitam ao professor estar aperfeiçoando seus estudos através de projetos de capacitação profissional. Há também investimentos didáticos, além do livro didático público há disponível uma biblioteca disciplinar.

Os ambientes criados com os recursos das TICs estão se transformando em meios importantes de aprendizagem. Onde os ambientes virtuais de aprendizagem oferecem aos professores e alunos um lugar onde a troca de informações, a pesquisa, a construção de projetos, o desenvolvimento do saber desafia os limites históricos de tempo e espaço. As tecnologias educacionais não criam ambientes que prescindem do professor, este sempre terá um papel fundamental no processo institucional do ensino.

O conceito de ensinar está diretamente ligado ao professor que, por suas ações, transmite conhecimentos e experiências a um aluno que tem por obrigação receber, absorver e reproduzir as informações recebidas. Todavia, através das novas tecnologias, o professor tem a oportunidade de realizar seu verdadeiro papel: o de mediador entre o aluno e sua aprendizagem, o facilitador e motivador, tornando professor e aluno continuamente aprendizes.

(...) encontraremos em algumas situações, por exemplo, a convicção de que o papel da escola em todos os níveis é o de 'educar' seus alunos, entendendo por 'educação' transmitir um conjunto organizado e sistematizado de conhecimentos de diversas áreas, desde a alfabetização, passando por matemática, língua portuguesa, ciências, história, geografia, física, biologia e outras, até aqueles conhecimentos próprios de uma formação profissional nos cursos de graduação de uma faculdade - e exigir deles 
memorização das informações que lhes são passadas e sua produção nas provas e avaliação. (MARON, 2007, p. 133 e 134)

O aluno, num processo de aprendizagem, assume papel de aprendiz ativo e participante, não mais passivo e repetidor, ele é um sujeito de ações que o leva a aprender e ao mudar seu comportamento, vê o professor e os colegas como parceiros idôneos dispostos a colaborar com a sua aprendizagem.

No se puede educar para convivir si no se educa en la cooperación y participación colectiva, en el ínter aprendizaje [...] La propuesta considera al grupo como un ambito privilegiado para el interaprendizaje entendido como recreación y producción de conocimientos, por la dinámica y la riquez que aporta através de la confrantación de ideias y opiniones proprias de las experiencias previas de cada participante: la possibilidad del logro de consensos y disensos en una dinámica permanente de acción-reflexión-accion. (MORAN, 1995, p. 141)

Para os educadores, em geral, essas mudanças de atitudes não são fáceis, estes estão acostumados a sentirem-se seguros com o papel tradicional de comunicar ou transmitir algo que se conhece muito bem, e ao sair dessa posição corre-se o risco de ouvir uma pergunta a qual não saiba da resposta imediatamente propondo aos alunos uma busca coletiva por uma resposta, tudo isso pode gerar uma grande desconforto e insegurança, (...) a informática na educação esta associada a mudança de como se aprende, a mudança de inovação entre quem aprende e quem ensina, a mudança do modo como se reflete o conhecimento. (CHAVES, 2006, p. 163).

O papel do professor não é o de detentor de conhecimento, mas de estar aberto para aprender com novas informações conquistadas junto com seus alunos, demonstrando condição de discutir e debater informações com eles desenvolvendo a criticidade, sabendo distinguir as informações recebidas. Para tanto o professor deve entender e viver a aprendizagem como interaprendizagem.

\section{Conclusão}

Constatou-se que a maioria dos pesquisados, atribui um grau relevante de importância à utilização das tecnologias, sendo que os mesmo afirmam que estas influenciam no 
processo de ensino-aprendizagem, promovendo melhoria na participação e motivação dos educandos. Sabe-se que existem muitos outros fatores que interferem no contexto da informática educativa nas escolas e que não foram considerados no âmbito dessa pesquisa. No entanto, é perceptível que o processo educativo está passando por um processo de contextualização que veio requerer a imersão das ações pedagógicas no rol das novas tecnologias, dispostas nos diferentes meios e que hoje se encontram nos ambientes escolares como instrumentos propulsores dos novos modelos de ensino aprendizagem.

Cientes que não é a tecnologia que vai resolver ou solucionar o problema educacional do Brasil, entretanto poderá colaborar se for usada adequadamente, para o desenvolvimento educativo de nossos estudantes, como elemento que contribua para a superação dos obstáculos que surgem na relação entre educação e tecnologia. Na realidade não se trata apenas de tecnologia com barreira, mas os obstáculos que tem a ver com as nossas mentes, pois utilizar as TICs significa abandonar certos hábitos e técnicas, que fazem alguns educadores se sentirem pouco a vontade diante do emaranhado de instrumentos que chegou ao espaço educativo nos últimos tempos. Esta inclusão da tecnologia implica necessariamente uma transformação profunda na maneira de ensinar e aprender.

Para tanto, recomenda-se que os novos projetos que ganham ênfase a cada dia envolvendo as redes sociais e softwares educacionais sejam desenvolvidos e os existentes expandidos, e que estes contemplem a nova relação professor e aluno, visto que o desafio dos professores hoje esta na maneira de ensinar que não se trata apenas de tecnologias com uso de computadores, mas de diferentes pontos de vista sobre as informações, e isso não significa só um novo conceito no que diz respeito à aprendizagem e ensino, mas também uma relação diferente entre professor e aluno. Onde aluno busca uma parceria com o professor.

Almeja-se diante desse processo que os cursos superiores que formam as áreas de licenciatura dêem ênfase a esta área para que em breve a educação deixe de ser um paradigma com conceitos pré-definidos em moldes tradicionais ou conteudistas, dando espaço aos diferentes saberes. Pois no ápice do atual tiroteio midiático, o educador conseguir, conscientizar-se e conscientizar seus pares acerca da validade da adoção de novas posturas metodológicas, como fomento na busca de novos conhecimentos e de aliar o processo educativo ao contexto social do qual nosso aluno é oriundo, estar-se-á dando o primeiro passo rumo a uma concepção de educação parte do século XXI. 


\section{REFERÊNCIAS}

Andre, Simone; Costa, Antonio Carlos Gomes da. (2004) Educação para o desenvolvimento humano. São Paulo: Ed. Saraiva.

Almeida, Maria Elizabeth Bianconcini de. (2006). Educação, ambientes virtuais e interatividade. In: Educação on-line. 2 ed. São Paulo: Edições Loyola.

Azevedo, Wilson. (2000, setembro). Muito além do jardim da infância - o desafio do preparo de alunos e professores on-line. Acesso em 15 de março de 2011, de http://www.revistaconecta.com/conectados/wilson muito alem.htm.

Chaves, Lupita. (2002). Develando la acción pedagógica en un salón de clase de educación inicial. Revista Actualidades Investigativas en Educación, 2(2). Recuperado el 12 de octubre de http://revista.inie.ucr.ac.cr/buscararticulos/controlador/Article/accion/show/articulo/develando-la-accion-pedagogica-enun-salon-de-clase-de-educacion-inicial.html

Burbules, Nicholas C. (1990, abril). Teaching and the tragic sense of education. Teaching College Record, p. 91.

Burbules, Nicholas C. e Torres, Carlos Alberto. (2004). Estado e Globalização: Uma introdução. In: Nicholas Burbules e Carlos Alberto Torres (ORGS). Globalização e Educação: perspectivas e críticas. Porto Alegre: Artmed.

Cervo, Amado L; Bervian, Pedro A. (1996). Metodologia científica. 4. ed. São Paulo: MAKRON Books.

Chaves, Eduardo. (2006). Educação Orientada para Competências e Currículo Centrado em Problemas. Acesso em 14 de junho de 2006, de http://www.escola2000.org.br/pesquise/texto/textos art.aspx?id=14

Chaves, Eduardo. (2004). Sua Escola a 2000 por Hora: Educação para o desenvolvimento humano pela tecnologia digital. São Paulo: Ed. Saraiva/Instituto Ayrton Senna.

Chaui, Marilena. (1997). Convite à Filosofia. São Paulo. Ática.

Garcia, Lenise Aparecida Martins. (2006). Competências e habilidades: Você sabe lidar com isso? Acesso em junho de 2006, de http://www.escola2000.org.br/pesquise/texto/textos art.aspx?id=36.

Lévy, Pierre. (1993). As tecnologias da inteligência. O futuro do pensamento na era da informática. São Paulo: Editora 34.

Marconi, Marina de A.; Lakatos, Eva M. (2007). Técnicas de pesquisa. São Paulo: 6.ed. Atlas. 
Marconi, Marina de A.; Lakatos, Eva M. (2009). Fundamentos de metodologia científica. São Paulo: 6. ed., Atlas.

Maron, Jose Manuel; Masetto, Marcos Tarciso; Behrens, Marilda Aparecida. (2007). Novas Tecnologias e Mediação Pedagógica. Campinas - São P: 13 ed., papirus.

Maia, Carmen; Mattar, João. (2008). ABC da EaD - A educação a distância hoje. São Paulo: Pearson.

Masetto, Marcos. (2007). Mediação pedagógica e o uso da tecnologia. In: Jose Manuel Moram, Marco Tarciso Massetto y Marilda Aparecida Behrens, Novas Tecnologias e Mediação Pedagógica (6ta. Ed). Campinas: Ed. Papirus.

Mecado, Luis Paolo L. (2002). Novas tecnologias na educação: reflexão sobre a prática. Maceió: Edufal.

Mec - Ministério da Educação e Cultura. (2006). Programa de Formação Continuada Mídias na Educação. (Módulo introdutório, Básico e intermediário) Brasília: MEC/SEED.

Moran, Jose Manuel. (1995, setembro/outubro). Novas tecnologias e o reencantamento do mundo. Tecnologia educacional, 23(126).

Perrenoud, Philippe. (2000). Dez Novas Competências para Ensinar (3ra ed). Porto Alegre: Artes Médicas Sul.

Rauen, Fábio José. (1999). Elementos de iniciação à pesquisa. Rio do Sul, SC: Nova Era.

Sampaio, Marisa N.; Leite, Ligia S. (1999). Alfabetização Tecnológica do Professor (5a. ed.). RJ; Vozes: Petrópolis.

Saviani, Dermeval. (1991). Pedagogia Histórico - critica: Primeiras aproximações. São Paulo: 3 ed., Cortez.

Silva, Marco (org). (2006). Educação on-line (2ª ed.). São Paulo: Edições Loyola.

Tajra, Sammya Feitosa. (2001). Informática na Educação: novas ferramentas pedagógicas para o professor da atualidade (3a. ed.). São Paulo: Érica.

Zabalza, Miguel A. A. (2004). O ensino universitário: seu cenário e seus protagonistas. Porto Alegre: Artmed, 2004. 